\title{
Feasibility study of the ultrasonic vibration assisted drilling of Inconel superalloy
}

\author{
Y.S. Liao ${ }^{\text {a }}$, Y.C. Chen ${ }^{\text {b,* }}$, H.M. Lin ${ }^{\mathrm{c}}$ \\ ${ }^{a}$ National Taiwan University, Taipei, Taiwan, ROC \\ ${ }^{\mathrm{b}}$ MSL/ITRI, R. 183, Bldg. 11, 195, Sec. 4 Chung Hsing Rd. Chutung, Hsinchu, Taiwan 310, Taiwan, ROC \\ ${ }^{\mathrm{c}}$ Nan Kai Institute of Technology, Nantou, Taiwan, ROC
}

Received 17 October 2006; accepted 5 February 2007

Available online 24 February 2007

\begin{abstract}
The ultrasonic vibration assisted drilling of Inconel 718 superalloy is studied in this paper. The tool holder of a machining center is retrofitted so that axial resonant vibration can be provided. Experimental results show that the chip size is reduced, and the variation of torque in drilling becomes smaller. These phenomena are particularly apparent at the final stage of a drill's usable life. It is also found that there is little improvement in drilling performance when the frequency of the ultrasonic vibration is varied. On the contrary, a drill's life is greatly increased when the vibration with a smaller amplitude is applied. But too large a vibration amplitude, such as over $12 \mu \mathrm{m}$ in this study, could lead to negative effects. For the testing conditions, the frequency of $31.8 \mathrm{kHz}$ and the amplitude of $4 \mu \mathrm{m}$ result in the best drill life and quality of the drilled hole in this study. Under this condition a drill's life is prolonged by as much as 2.7 times of that without vibration assisted drilling process. Concerning drilling efficiency, it is found that by applying ultrasonic vibration assisted drilling, lifting of the drill for chip removal as commonly employed in conventional drilling of a high aspect ratio hole is not necessary, and saving of the working time is obtained.
\end{abstract}

(C) 2007 Elsevier Ltd. All rights reserved.

Keywords: Ultrasonic vibration assisted drilling; Inconel 718; Chip removal

\section{Introduction}

Nickel-based superalloy Inconel 718 has been widely applied in aerospace and other industries for years due to its excellent mechanical properties at low and intermediate temperature $\left(-250\right.$ to $\left.700{ }^{\circ} \mathrm{C}\right)$. The resulting high temperature in cutting due to its superior temperature properties together with serious work hardening, and hard to break and sticking chip on the tool face make Inconel 718 one of the difficult-to-cut materials. This is particularly true in drilling operation as the chip formation process takes place at the cutting edges which are inside the hole being drilled, the condition that is unfavorable for both chip and heat removals. According to the reported study by the authors [1], BUE formed in the drilling process, and caused wear of cutting edges and increase of thrust force and torque. Long

\footnotetext{
*Corresponding author. Tel.: + 8863 5919377. fax.: + 88635820454 .

E-mail address: tony0107@itri.org.tw (Y.C. Chen).
}

chips formed when there was damage of cutting edges after serious wear. Finally, the drilling process would be interrupted and no longer be effectively continued because of the breakage of cutting edge and difficulty in chip removal. As a result, it is found that the removal of chips greatly influenced the cutting process and tool life. Hence, lowering the friction force at work-tool interface is essential to improve drilling efficiency. In this regard, peck drilling is commonly employed in drilling operation.

The concept of the use of vibration to assist chip removal in drilling was first proposed by Kumabe [2]. Zhang et al. [3] had proved that the application of $16 \mathrm{kHz}$ ultrasonic vibration on the workpiece has the effect of increasing the rigidity of the drill, reducing the drill skidding and size errors of the drilled hole, and increasing the drill life. By analyzing the chip path and geometry in axial vibration drilling of soft and tough materials, Zhang and Wang [4] proposed a new chip breaker. They also applied the vibration to the drilling of FRPs, and found that 
delamination problem was improved [5]. Toews, Compton and Chandrasekar [6] had imposed a lower frequency vibration on the workpiece in their experiment, and they found that drilling force would decrease when the vibration frequency was properly set. In studying rotary ultrasonic machining of titanium alloy, Churi, Pei and Treadwell [7] found that ultrasonic power had significant effects on cutting force and surface roughness. A too large or too small power would deteriorate the process.

There have been very few studies on the ultrasonic vibration assisted drilling of work-hardening materials to date. Its mechanism in quality improvement of the drilled hole has not been investigated either. The purpose of this paper is to study the feasibility of applying ultrasonic vibration for drilling of Inconel 718. The role it plays and the effects of the amplitude and frequency of the oscillator on the drilling performance are studied as well.

\section{Experiment setup}

A V65 machining center built by Victor Taichung Machinery, Taiwan was employed to drill $30 \mathrm{~mm}$ depth holes on solid-solution Inconel 718 block having an average hardness of $\mathrm{HRc} 40$. To supply ultrasonic vibration in drilling process, the interior of a BT40 chuck was modified so that a piezoelectric crystal oscillator could be fitted in and mounted properly between the chuck and collect. Power of $300 \mathrm{~W}$ was provided via a carbon brush in contact with the coil around the tool holder. By this arrangement, experiments were conducted more conveniently since the resonant frequency could be maintained irrespective of the size of the workpiece being drilled. There were two ranges of oscillating frequency adjustable for the oscillator we used. In order to achieve resonance at the drill tip the overhangs of the drill should be properly adjusted. For the higher frequency range, it was found that the overhang of $70 \mathrm{~mm}$ satisfies resonance condition [8], and the corresponding resonant frequency was $31.8 \mathrm{kHz}$. Similarly for the lower frequency range the overhang of $130 \mathrm{~mm}$ was chosen, and the associated frequency was $20.3 \mathrm{kHz}$. The oscillating amplitude adjustable for these two frequencies were $4-12$ and $8-17 \mu \mathrm{m}$, respectively. A Kistler type 9273 dynamometer was mounted under workpiece fixture to record the torque and thrust force during the process. Sampling interval and total sampling time per record were $4 \mathrm{~ms}$ and $40 \mathrm{~s}$. The cutting fluid (Brugarolas BESOL 346) containing nano-particle surface modifier (Energy Release, USA) was applied during the drilling process. The drill used was tungsten carbide with a diameter of $10.5 \mathrm{~mm}$. The cutting speed and feed were $400 \mathrm{rpm}(13.2 \mathrm{~m} / \mathrm{min})$ and $40 \mathrm{~mm} / \mathrm{min}(0.1 \mathrm{~mm} / \mathrm{rev})$, respectively. In all experiments peck drilling for chip removal was employed. In peck drilling the preparatory function G83 was used. The drill starts its drilling cycle from zero point position which is $2 \mathrm{~mm}$ above the workpiece surface. Once $5 \mathrm{~mm}$ depth has been drilled by the given feed, a fast retract speed of $1000 \mathrm{~mm} / \mathrm{min}$ is taken to lift the drill back to the zero point. The drill then moves downward with a fast feed speed of $1000 \mathrm{~mm} / \mathrm{min}$ until it is $2 \mathrm{~mm}$ above the contacting point where a slow feed speed of $150 \mathrm{~mm} / \mathrm{min}$ takes over to bring the drill to the next start drilling position. The cycle is repeated until $30 \mathrm{~mm}$ drilling depth has been completed. This resulted in extra $20 \mathrm{~s}$ needed in drilling one hole as compared with the conventional drilling. Based on our previous study, for the size of the drill and the drilling conditions we used the rise of torque to $1000 \mathrm{Ncm}$ had been found as the end of the drill life [1]. The number of holes drilled when this value is reached is taken to determine the tool life in this study.

\section{Experimental results and discussions}

\subsection{Effects of ultrasonic vibration on drilling}

The effect of high frequency ultrasonic vibration on drilling is studied according to the chip morphology, the variation of cutting force and the tool wear. The very first observation of the difference as comparing with that without vibration assisted is the chips generated. They are segmented to shorter length and even to small pieces. Fig. 1 shows the chips obtained under nonvibratory and vibration-assisted drilling. It can be seen that the proportion of small size chips increases when the ultrasonic vibration is applied. This is particularly true at the final stage of a drill's life where long continuous chips start forming, high-frequency movement of the drill helps in breaking long chips into pieces. Similar result was observed by Neugebauer and Stoll [9]. The average thrust force and
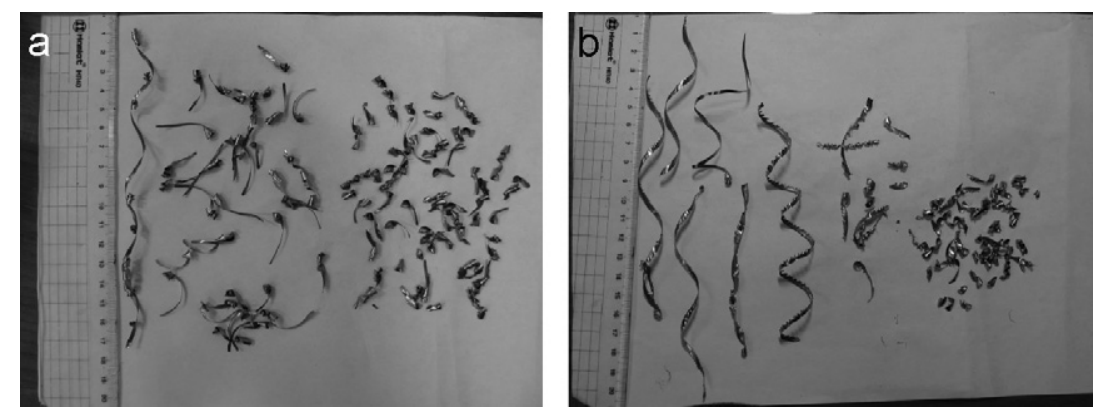

Fig. 1. Chips collected in (a) nonvibratory drilling and (b) ultrasonic vibration assisted drilling. 
torque at different holes being drilled by the same drill under the ultrasonic vibration assisted condition are shown in Fig. 2. For comparison purpose, those under nonvibratory drilling condition are given in the same figure. It is noted that the average thrust force is smaller than that without vibration applied irrespective of the number of holes being drilled. This is readily understood since the resistance of chip disposal is reduced owing to smaller size chips in the flute of a drill which in turn reduces the thrust force. Similar view was proposed also by Chang and Bone [10] and Ma et al. [11]. Since the chips can move more easily in the flute, it is found that the BUE which occurs commonly in nonvibratory drilling would not appear until a number of holes have been drilled by the same drill. To check the effect of thrust force induced by the rapid movement of the drill due to ultrasonic vibration, experiments by pressing the drill against the workpiece while applying ultrasonic vibration with the frequency $31.8 \mathrm{kHz}$ and various amplitudes were conducted. The variation of impact force is shown in Fig. 3. In the figure one division is $2.8 \mathrm{~N}$, and the impact force is about $12 \mathrm{~N}$ when the vibration with amplitude of $8 \mu \mathrm{m}$ was applied. This is far smaller than $1600 \mathrm{~N}$, the force in vibrationassisted drilling (referring to Fig. 2). Hence it is concluded that the contribution of thrust force due to the impact force resulting from ultrasonic vibration is negligible.

Comparatively, there is no significant difference in the torques of two drilling processes before drilling of 30 holes by the same drill. The morphologies of the resulting chip and tool wear at different stages of a drill are given in Fig. 4. Chip thickness at the initial stage under both conditions is similar. After drilling 20 holes by nonvibratory drilling as shown in Fig. 4(a), chipping appears at the periphery of the cutting edge, which leads to a larger
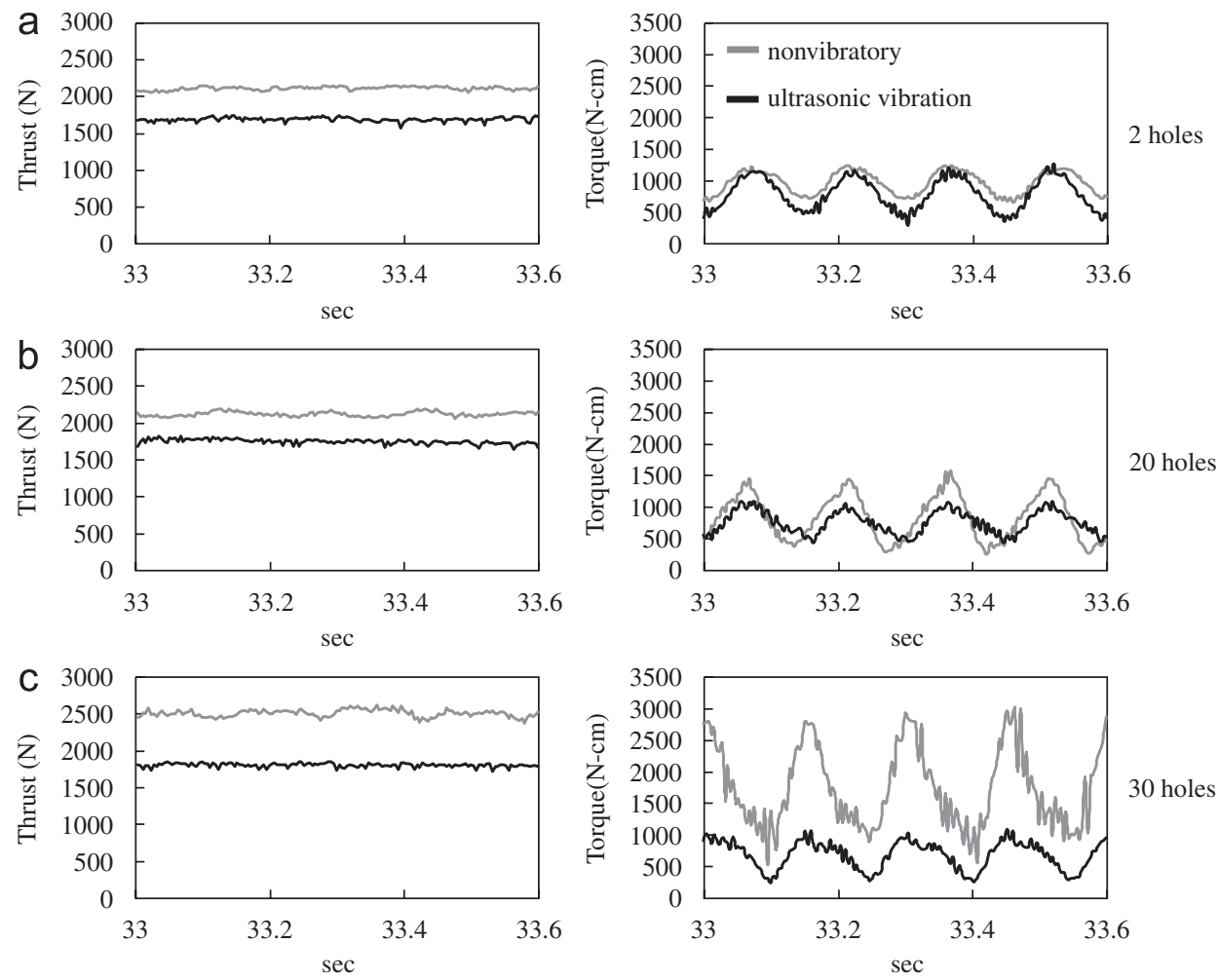

Fig. 2. Thrust force and torque when the same drill has been used in drilling different number of holes (ultrasonic vibration condition: $31.8 \mathrm{kHz}$ frequency and $8 \mu \mathrm{m}$ amplitude).
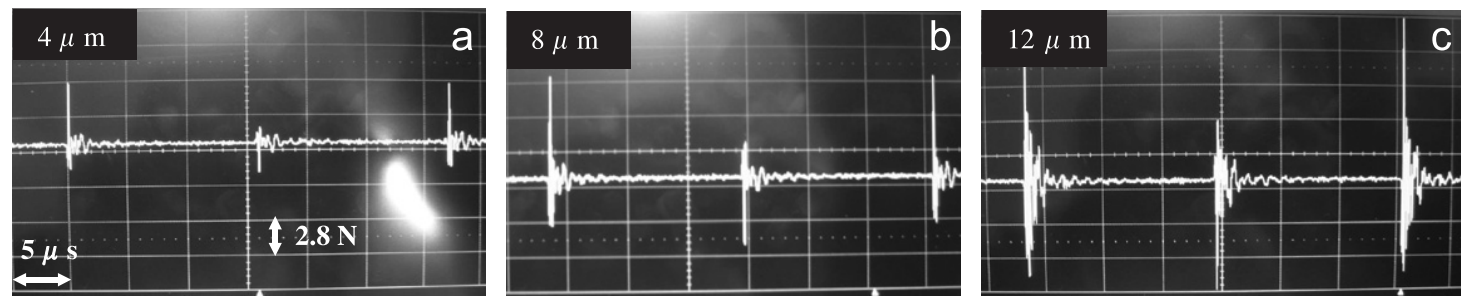

Fig. 3. Voltage signal of impact force induced by $31.8 \mathrm{kHz}$ ultrasonic vibration with the amplitude of (a) 4 , (b) 8 , and (c) $12 \mu \mathrm{m}$. 

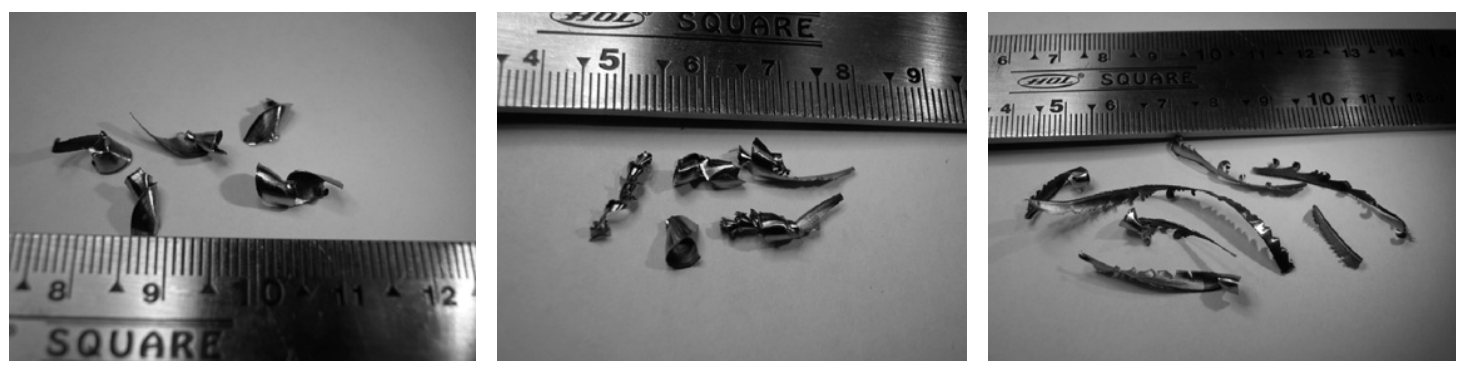

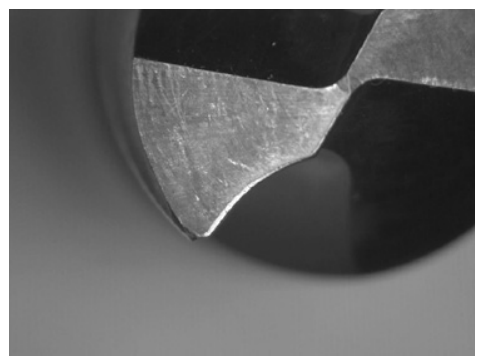

2holes

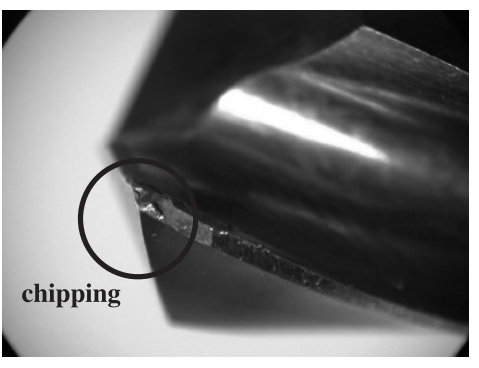

20holes

Nonvibratory drilling

a
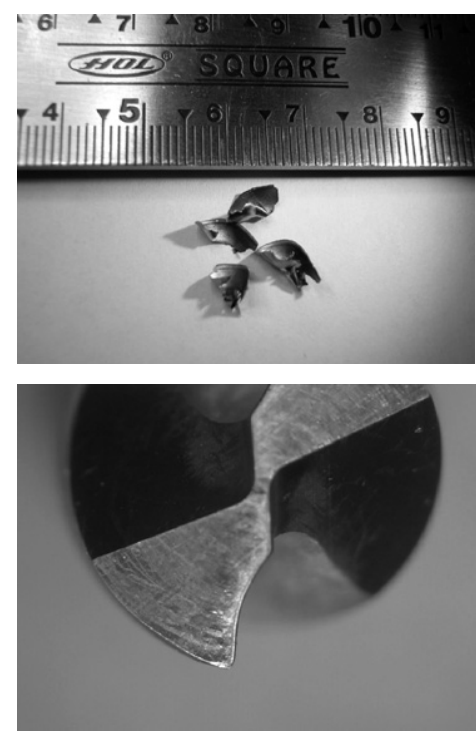

2holes

b

Ultrasonic vibration assisted drilling
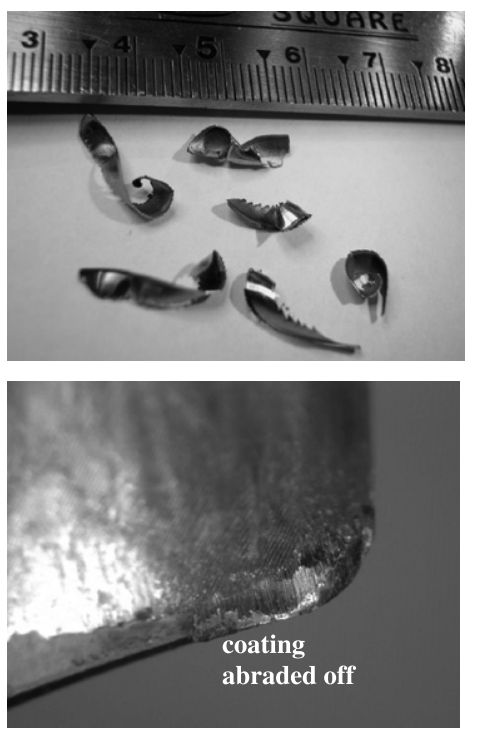

20holes

30holes
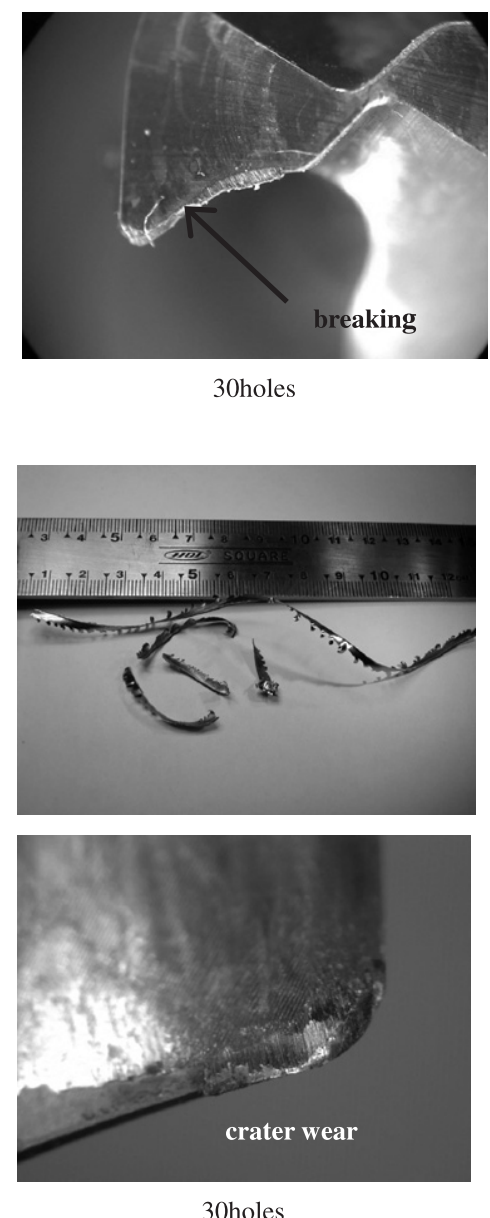

30holes

Fig. 4. Photographs of chips and tool wear at different stages of a drill's life, (a) nonvibratory drilling and (b) ultrasonic vibration assisted drilling.

variation of torque (referring to Fig. 2(b)). As for the ultrasonic vibration drilling, the variation of torque is considerably smaller because the smaller size chips can move more easily and stably. The decrease of thrust force results in less chipping of cutting edge and smaller variation of torque. In addition, it is found that the chip thickness is only three-fourths of the chips in nonvibratory drilling. There is only a little abrasion of the coating layer on the flank face of the drill at this stage.

As the drill is close to the end of its usable life in nonvibratory drilling, long continuous chips start forming and disturbing the drilling process. This, in turn, results in an enormous fluctuation of torque as shown in Fig. 2(c). The drill life in terms of the number of holes that can be drilled by a drill is 29 in this case. On the contrary, following the same reasoning as described previously the torque only increases slightly with almost no change of fluctuation during the drilling process when the ultrasonic vibration is applied. The chip is half in length of that of nonvibratory drilling. The tool wear photographs in Fig. 4(b) show that a small part of cutting edge near periphery has damaged.

Based on the above observations, it is concluded that ultrasonic vibration in drilling of Inconel 718 can segment the long continuous chips and reduce chip size, and also help the removal of chips from the cutting zone. Thus the thrust force is reduced and the rise of torque is delayed. As a result a longer tool life is obtained. 


\subsection{Effects of the amplitude and frequency of ultrasonic vibration on drilling of Inconel 718}

The relations between tool life in terms of the number of holes that can be drilled by the same drill and two parameters of vibration are obtained and plotted in Fig. 5. For comparison purpose, tool life of 29 holes that corresponds to nonvibratory drilling case is also given in the figure. It can be seen that the number of holes that can be drilled by a drill increases with decrease of vibration amplitude and increase of vibration frequency. When the vibration amplitude is $12 \mu \mathrm{m}$ the tool life is 35 holes and 29 holes for the vibration frequencies of 31.8 and $20.3 \mathrm{kHz}$, respectively. Considering the tool life of these two vibration frequencies and the tool life of nonvibratory drilling, it is noted that the vibration amplitude should be smaller than $12 \mu \mathrm{m}$ to ensure there is positive effect of vibration on tool life.

Analysis of variance (ANOVA) for evaluating the significance level of vibration amplitude and frequency on tool life (in terms of total number of holes that can be drilled) is given in Table 1. The criterion for a confidence level of $95 \%$, or $P$-value less than 0.05 , is used to determine if the specific factor is significant. It is revealed from Table 1 that for the amplitude and frequency levels we used in the experiments, amplitude has a significant influence on tool life while frequency is insignificant. In other words, vibration amplitude has more effect than frequency on tool life in our study. Variations of thrust force with respect to number of holes being drilled for various vibration amplitudes under the frequencies of 20.3 and $31.8 \mathrm{kHz}$ until the end of tool life are given in Figs. 6(a) and (b), respectively. The larger scattering of the data could be due

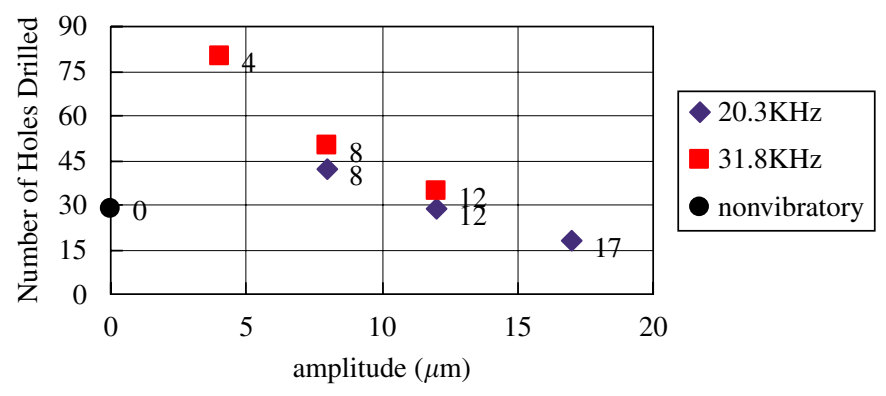

Fig. 5. Relations of the tool life with vibration amplitude and frequency. to less stiffness of the modified tool holder. However the increasing trend can still be vaguely seen, hence the overall features of the drilling forces still inhere in the collected data. There is no much difference of thrust force from the first hole to the last hole drilled. This is because the change of thrust force with the progress of tool wear is small, and it is not apparent to indicate the end of tool life. Instead, the variation of torque is larger and more violent during the drilling process, particularly close to the end of tool life (referring to Ref. [1]), and this can be also seen later in Fig. 8.

It can be seen that the thrust force in vibration-assisted drilling increases with increasing order of amplitude. The thrust force for the amplitude of $12 \mu \mathrm{m}$ is more or less the same as that in nonvibratory drilling, while it is larger than that of nonvibratory drilling when the amplitude is $17 \mu \mathrm{m}$. It was described previously, the application of ultrasonic vibration in drilling facilitates chip disposal and reduces thrust force as a result. However, since the vibration frequency is far faster than the chip velocity, it is reasonable to infer that the larger amplitude would make the transport of chip more difficult under the same frequency. Besides, the application of ultrasonic vibration also induces small value impact force. The impact force increases with the increase of amplitude. Specifically, as shown in Fig. 3 they are 6, 12, and $18 \mathrm{~N}$ for the amplitudes of 4,8 , and $12 \mu \mathrm{m}$, respectively. Hence, thrust force would rise with increasing amplitude. For the amplitude of $12 \mu \mathrm{m}$, there is less reduction of thrust force because of less effective chip disposal. It may also be offset by the impact force and the extra force caused by more possible drill wear resulted from the larger impact force. Hence the thrust force is similar to that without vibration-assisted drilling. When the amplitude is further increased to $17 \mu \mathrm{m}$, damage of the drill takes place easily due to too large impact forces. This together with less effective chip disposal results in a thrust force larger than nonvibratory case even at the beginning of drilling. The number of the holes that can be drilled is 18, which is only about two-third of that in nonvibratory drilling. The same tendency depicted in thrust force in drilling is observed in the quality of the drilled hole in terms of its surface roughness as shown in Fig. 7. The torque vs. number of holes drilled with various amplitudes is given in Fig. 8. As seen in this figure, the amplitude has little effect on torque since the drill is oscillating in the axial direction. It is also noted the torque increases to a larger value before the end of tool life [1].

Table 1

Analysis of variance for a drill's usable life

\begin{tabular}{llllll}
\hline Source & Sum of squares & $\mathrm{d} f$ & Mean square & $F$ & $p$-value \\
\hline Model & 2300.33 & 4 & 575.08 & 575.0833 & 0.0313 \\
A-amplitude & 1337.67 & 3 & 445.89 & 445.8889 & 0.0348 \\
B-frequency & 49 & 1 & 49 & 49 & 0.0903 \\
Residual & 1 & 1 & 1 & & Significant \\
Cor. total & 2301.33 & 5 & & & \\
\hline
\end{tabular}



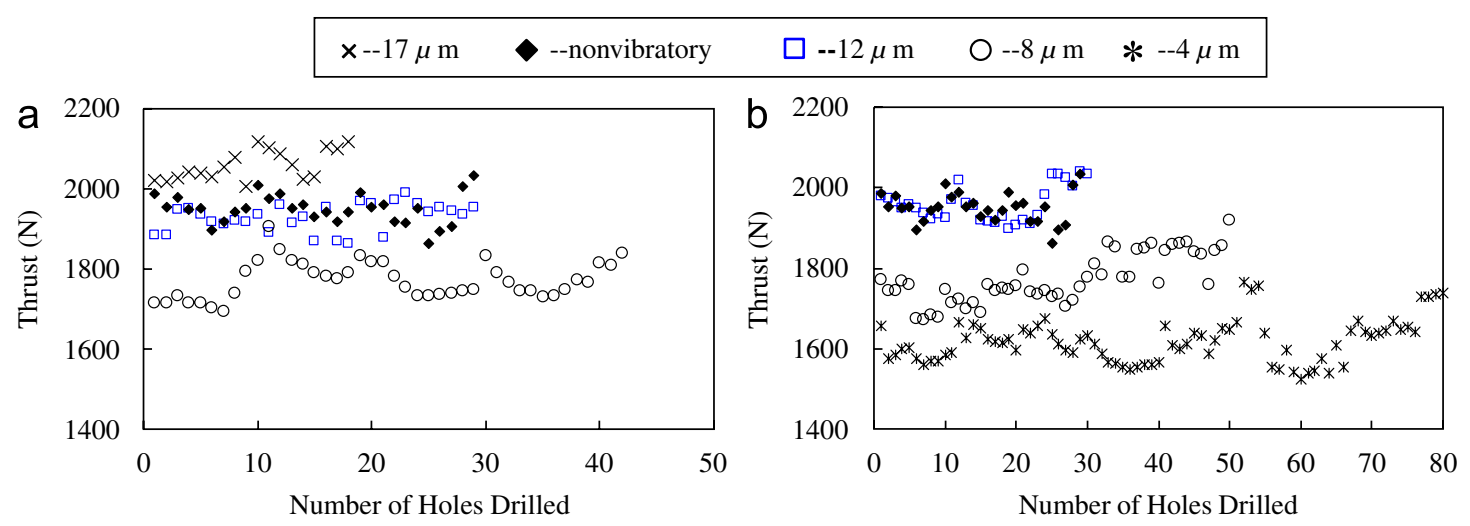

Fig. 6. Thrust force in drilling under various combinations of vibration amplitude and frequency.
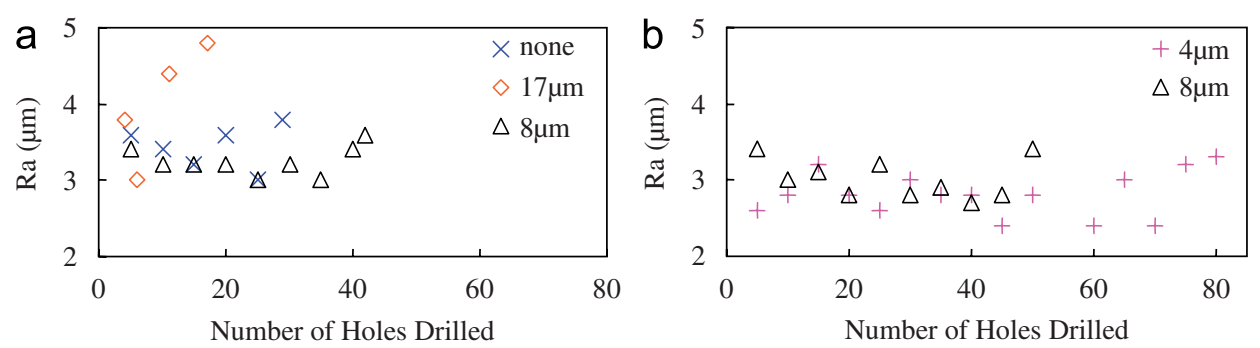

Fig. 7. Surface roughness in drilling under various combinations of vibration frequency and amplitude.

a

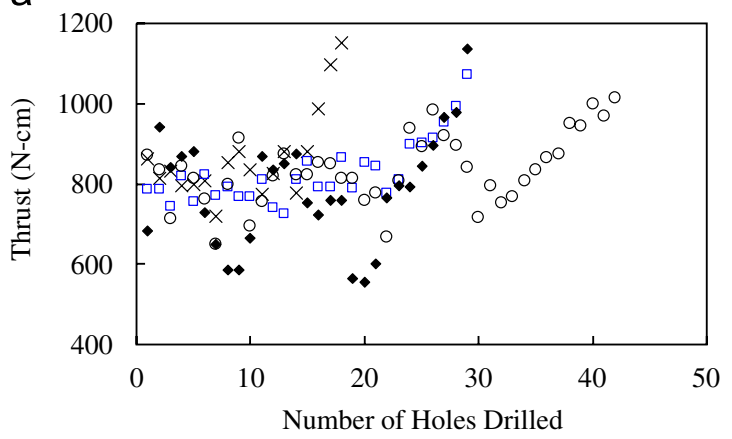

b

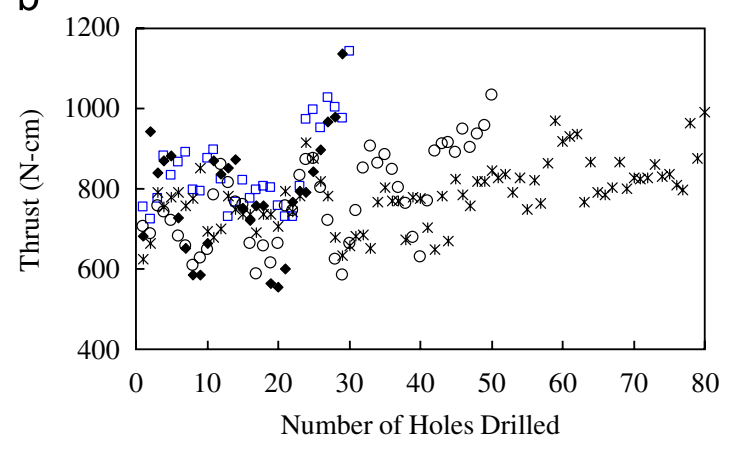

$$
\times--17 \mu \mathrm{m} \quad \text {--nonvibratory } \quad \square--12 \mu \mathrm{m} \quad \bigcirc-8 \mu \mathrm{m} \quad *--4 \mu \mathrm{m}
$$

Fig. 8. Torque in drilling under various combinations of vibration amplitude and frequency.

The effect of frequency on thrust force under various amplitudes is also given in Figs. 6(a) and (b). There is no much difference in thrust force under the same amplitude condition for the two frequencies used in this study. Since the reciprocating movement of the drill resulting from the supplied ultrasonic vibration can be imaged as a knife chopping chips intermittently, it is expected the frequency would be related to the chips generated. In this regard, a higher frequency is beneficial since it may result in shorter chips and easier chip disposal. Lubrication could be more effective because there is a higher chance for the cutting fluid to flow into the cutting zone. In addition, it is less likely for the chips to adhere on the tool when there is a higher-frequency movement of the tool. As a result formation of BUE on the tool face is more difficult when a higher frequency is applied. Figs. 9(a) and (b) show the side view and end view of the worn drill when ultrasonic vibration of the frequency of 20.3 and $31.8 \mathrm{kHz}$, respectively, is applied in drilling. On comparing these two figures it is noted that there is a large amount of BUE forming on the tool face near cutting edge and causes serious tool wear when ultrasonic vibration of a lower frequency is applied. This is confirmed by Fig. 5 where a higher frequency results in a little bit better tool life than that of a lower frequency. Besides, the machined surface finish is deteriorated as can be vaguely seen in Fig. 7.

Based on the above discussions, it is concluded that a smaller amplitude and a higher frequency are more appropriate for ultrasonic vibration-assisted drilling of Inconel 718 as long as it results in more effective chip 
disposal than nonvibratory drilling. Out of the combinations of the frequency and amplitude we used in the experiments, the amplitude of $4 \mu \mathrm{m}$ and frequency of $31.8 \mathrm{kHz}$ resulted in the best drill performance. Under this condition, the service life of the drill is 80 holes (referring to Fig. 5). Compared with 29 holes of the nonvibratory drilling condition, the tool life is extended by as much as 2.7 times. The average surface roughness $\mathrm{Ra}$ is within the range of $2-3 \mu \mathrm{m}$ and the measured roundness error is lower than $0.03 \mathrm{~mm}$.

\subsection{Efficiency of ultrasonic vibration assisted drilling}

It is common practice to apply peck drilling in deep-hole drilling operation. This action helps chip removal but total machining time is increased as a consequence. Series experiments are conduced to test if ultrasonic vibration assisted drilling can achieve the similar function of peck drilling. In the experiment an aircraft used component which requires drilling of 80 blind holes with $30 \mathrm{~mm}$ depth is tested. The peck drilling conditions used in all experiments are described in Section 2. Details of the peck drilling of one hole are given in Table 2. From this table one can see that it takes 7 pecks to complete drilling one hole. The total traveling distance for fast feed speed is $93+137=230 \mathrm{~mm}$, and for slow feed speed it is $2 \times 7=14 \mathrm{~mm}$. Since the feed used in drilling is $40 \mathrm{~mm} /$ min, the fast feed speed and slow feed speed are1000 and $150 \mathrm{~mm} / \mathrm{min}$, respectively, then the time spent in actual drilling is $30 / 40=0.75 \mathrm{~min}$, and the time spent in moving the drill is $(230 / 1000)+(14 / 150)=0.32 \mathrm{~min}$. The total machining time needed to drill one hole will be
$0.75+0.32=1.07 \mathrm{~min}$. For conventional drilling, the drill is brought to the workpiece surface in drilling every hole with the slow feed speed, hence the machining time will be $(30 / 40)+(2 / 150)=0.76 \mathrm{~min}$.

Table 3 shows the results under various drilling conditions. In the table, mode $\mathrm{A}$ is ultrasonic vibration assisted peck drilling, mode $\mathrm{B}$ is peck drilling without ultrasonic vibration assisted, mode $\mathrm{C}$ is ultrasonic vibration assisted conventional drilling, and mode $\mathrm{D}$ is the conventional drilling. In computing the total working time given in the table it is assumed that the preset time in ultrasonic vibration assisted peck drilling can be neglected and the tool changing time is $30 \mathrm{~s}$. Noting the tool life of 80 holes when ultrasonic vibration with the frequency of $31.8 \mathrm{kHz}$ and amplitude of $4 \mu \mathrm{m}$ is applied has been described previously in Section 3.2. The tool life of 29 holes by the use of peck drilling only also has been mentioned. The tool life by ultrasonic vibration assisted conventional drilling, and by conventional drilling was found to be 31 and 9 holes, respectively. Comparing ultrasonic vibration assisted peck drilling (i.e. mode A) with peck drilling (i.e. mode B), the total working time is about the same, but the improvement of tool life is very significant. In comparison ultrasonic vibration assisted conventional drilling (i.e. mode C) with peck drilling (i.e. mode B), there is no much difference in the number of holes that can be drilled by a drill, but the time needed to drill a hole is less. This leads to a less total working time of $61.8 \mathrm{~min}$ as compared with $86.6 \mathrm{~min}$ needed by the use of peck drilling to complete drilling 80 holes. In other words $28.6 \%$ reduction of the total working time can be achieved. Hence the conventional drilling is even advantageous over
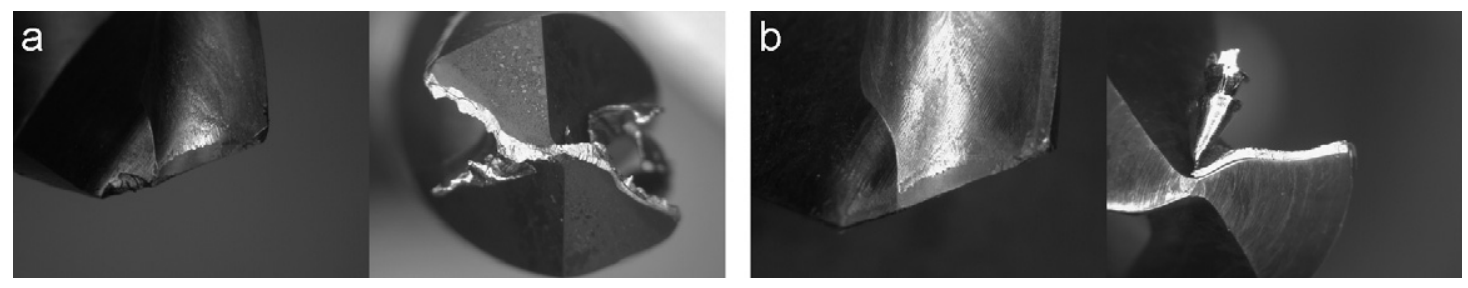

Fig. 9. Photographs of the worn drill when vibration of $8 \mu \mathrm{m}$ amplitude and (a) 20.3 and (b) $31.8 \mathrm{kHz}$ frequency is applied.

Table 2

Details of peck drilling of one hole

\begin{tabular}{lllll}
\hline Peck no. & $\begin{array}{l}\text { Distance traveled downward with } \\
\text { fast feed speed }\end{array}$ & $\begin{array}{l}\text { Distance traveled downward with } \\
\text { slow feed speed }\end{array}$ & $\begin{array}{l}\text { Depth of the hole } \\
\text { drilled }\end{array}$ & $\begin{array}{l}\text { Distance traveled upward with fast } \\
\text { retract speed }\end{array}$ \\
\hline 1 & 0 & 2 & 3 & 5 \\
2 & 3 & 2 & 8 & 10 \\
3 & 8 & 2 & 13 & 20 \\
4 & 13 & 2 & 23 & 30 \\
5 & 18 & 2 & 28 & 32 \\
6 & 23 & 2 & 30 & 13 \\
7 & 28 & 2 & & \\
Sum of traveling & 93 & 14 & & \\
distance & & &
\end{tabular}


Table 3

Comparison of drilling performance under various drilling conditions in drilling 80 holes

\begin{tabular}{|c|c|c|c|c|}
\hline Mode & $\begin{array}{l}\text { A-vibration assisted } \\
\text { peck drilling }\end{array}$ & $\mathrm{B}$ - peck drilling & $\begin{array}{l}\mathrm{C}-\text { vibration assisted } \\
\text { conventional drilling }\end{array}$ & $\begin{array}{l}\mathrm{D} \text { _ conventional } \\
\text { drilling }\end{array}$ \\
\hline $\begin{array}{l}\text { No. of holes that can be drilled by a drill } \\
\text { (tool life) }\end{array}$ & 80 & 29 & 31 & 9 \\
\hline Machining time/each hole (min) & 1.07 & 1.07 & 0.76 & 0.76 \\
\hline No. of tool needed to drill 80 holes & 1 & 3 & 3 & 9 \\
\hline Total tool changing time (min) & $\mathrm{N} / \mathrm{A}$ & 1 & 1 & 4 \\
\hline Total working time $(\mathrm{min})$ & 85.6 & 86.6 & 61.8 & 64.8 \\
\hline
\end{tabular}

a

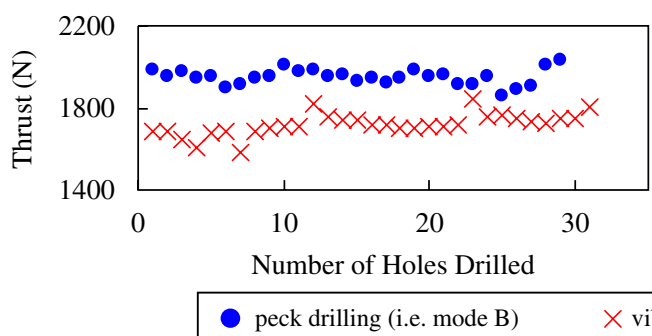

b

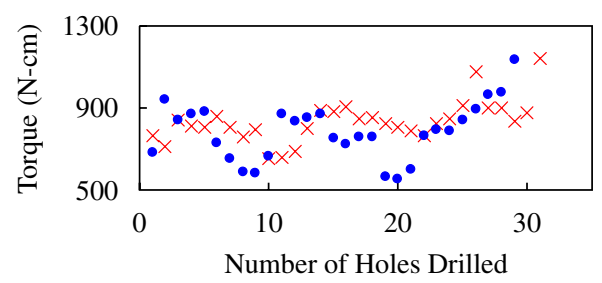

$\mathrm{X}$ vibration assisted conventional drilling (i.e. mode $\mathrm{C}$ )

Fig. 10. Thrust force and torque in peck drilling and vibration assisted conventional drilling (ultrasonic vibration condition: $31.8 \mathrm{kHz}$ frequency and $4 \mu \mathrm{m}$ amplitude).

peck drilling if vibration is applied. The thrust force and torque associated with these two drilling conditions are shown in Fig. 10. It can be seen from this figure that both the thrust force and torque are more stable when ultrasonic vibration is applied during the drilling process. To check if the improvement is still significant an extremely fast peck drilling condition is used. The fast feed and retract speed of $2000 \mathrm{~mm} / \mathrm{min}$ and slow feed of $200 \mathrm{~mm} / \mathrm{min}$ are chosen. These are about the limit speeds of the commercially available $\mathrm{CNC}$ machines. In this case a total drilling time of $75.8 \mathrm{~min}$ is still needed to complete drilling 80 holes when peck drilling (i.e. mode B) is used. There is still big difference of this value as compared with $61.8 \mathrm{~min}$ required by choosing ultrasonic vibration assisted conventional drilling (i.e. mode C) stated above. Hence even a very rapid peck drilling is used, its performance is still inferior to vibration assisted conventional drilling. On the other hand, when the vibration is assisted in conventional drilling (i.e. mode $\mathrm{C}$ ), the working time is about the same as that without vibration assisted (i.e. mode D), but it is still worth applying since the tool service time is longer and lesser tools are needed.

\section{Conclusion}

Feasibility study of the ultrasonic vibration assisted drilling of Inconel 718 superalloy is conducted. Experimental results show that the chip size is reduced and proportion of segmented chips is increased. The thrust force in drilling is reduced, there is less variation of the torque, and the usable life of the drill is prolonged. These phenomena are particularly apparent at the final stage of a drill's usable life. Vibration amplitude as compared with vibration frequency is proved to have a larger effect on tool life. A smaller amplitude and a higher frequency are more appropriate for ultrasonic vibration assisted drilling of Inconel 718. Positive effect on drilling performance can be obtained if the vibration amplitude is controlled under $12 \mu \mathrm{m}$. For the testing conditions, the frequency of $31.8 \mathrm{kHz}$ and the amplitude of $4 \mu \mathrm{m}$ result in the best drill life and quality of the drilled hole in this study. It is also found that the function of peck drilling that is commonly employed in drilling practice can be replaced by the ultrasonic vibration assisted conventional drilling (i.e. without pecking motion). The tool life is similar but $28.6 \%$ of the working time is saved. In summary, the application of ultrasonic vibration in drilling can prolong tool life and hence fewer tools are needed.

\section{References}

[1] Y.C. Chen, Y.S. Liao, Study on wear mechanisms in drilling of Inconel 718 superalloy, Journal of Materials Processing Technology 140 (2003) 269-273.

[2] J. Kumabe, Fundamentals and Application of Vibration Cutting, Jikkyo Publishing Co. Ltd., Japan, 1979.

[3] D.Y. Zhang, X.J. Feng, L.J. Wang, D.C. Chen, Study on the drill skidding motion in ultrasonic vibration microdrilling, International Journal of Machine Tools and Manufacture 34/6 (1994) 847-857. 
[4] D.Y. Zhang, L.J. Wang, Investigation of chip in vibration drilling, International Journal of Machine Tools and Manufacture 38/3 (1998) $165-176$.

[5] L.B. Zhang, L.J. Wang, X. Wang, Study on vibration drilling of fiber reinforced plastics with hybrid variation parameters method, Composites: Part A 34 (2003) 237-244.

[6] H.G. Toews, W.D. Compton, S. Chandrasekar, A study of the influence of superimposed low-frequency modulation on the drilling process, Precision Engineering 22/1 (1998) 1-9.

[7] N.J. Churi, Z.J. Pei, C. Treadwell, Rotary ultrasonic machining of titanium alloy: effects of machining variables, Machining Science and Technology 10 (2006) 301-321.
[8] Y.C. Chen, Y.S. Liao, J.D. Fan, Autoresonant tuning and control in ultrasonic vibration assisted drilling process, Material Science Forum 505-507 (2006) 823-828.

[9] R. Neugebauer, A. Stoll, Ultrasonic application in drilling, Journal of Material Processing Technology 149 (2004) 633-639.

[10] S.F. Chang, G.M. Bone, Burr size reduction in drilling by ultrasonic assistance, Robotics and Computer-Integrated Manufacturing 21 (2005) 442-450.

[11] C. Ma, E. Shamoto, T. Moriwaki, L. Wang, Study of machining accuracy in ultrasonic elliptical vibration cutting, International Journal of Machine Tools and Manufacture 44 (2004) $1305-1310$. 